surgery and use of drugs that modify disease as both measures are objective and unlikely to be omitted from case notes and may be required in severe chronic destructive disease. These measures were not associated with antinuclear antibody initially or subsequently, which is particularly notable as antinuclear antibody (and correlated rheumatoid factor) may be used as criteria for selection for surgery or second line drugs. The lack of correlation strongly suggests that the presence of antinuclear antibody initially is not an adverse prognostic indicator in rheumatoid arthritis; thus the test for antinuclear antibody is of little value in the routine assessment of straightforward rheumatoid arthritis.

We thank Drs R D Sturrock and H A Capell for allowing us to study their patients, and Mrs V Eardley for typing the manuscript.

1 Davis JS. Antinuclear antibodies. Textbook of rheumatology. Philadelphia: Saunders, 1981:691-709.

2 Condemni JJ, Barnett EV, Atwater EC, Jacox RF, Morgan ES, Vaughan $\mathrm{JH}$. The significance of anti-nuclear factors in rheumatoid arthritis. Arthritis Rheum 1965;8:1080-93.

${ }^{3}$ Arthritis Foundation. Primer on the rheumatic diseases. FAMA 1973;224: suppl 5.

4 Ward DJ, Johnson GD, Holborow EJ. Antinuclear factor in rheumatoid arthritis: its incidence and clinical significance. Ann Rheum Dis 1964; 23:306-10.

(Accepted 7 March 1984)

Centre for Rheumatic Diseases, University Department of Medicine, Glasgow G4 0EH

M M STEVEN, MRCP, senior registrar

L G TEH, MB, CHB, senior house officer

L S TEH, medical student

T PULLAR, MRCP, registrar

J J F BELCH, MRCP, lecturer

D LEWIS, FRACP, research registrar

J PARKER, MRCP, registrar

A ZOMA, MRCP, senior registrar
Correspondence to: Dr T Pullar.

In our case we discounted transmission of the maternal pulse through the dead fetus because of the discrepancy between the maternal pulse rate and the fetal heart rate when recorded simultaneously. Indeed, had we suspected intrauterine death initially we could have confirmed it by real time ultrasonography. In seeking an explanation for the trace we examined the scalp electrode and found that amniotic fluid had tracked up between the inner core and outer spiral of the

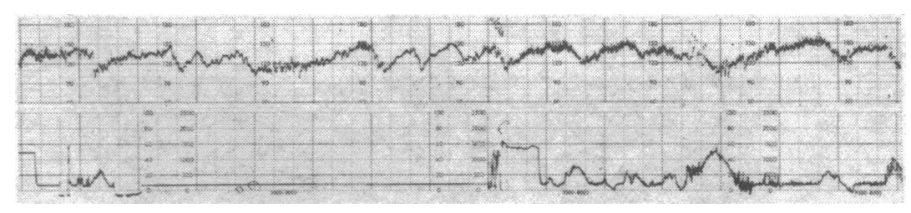

Fetal heart trace. Paper speed $1 \mathrm{~cm} / \mathrm{min}$.

electrode. This caused electrolytic activity between the differing metals of the electrode, which produced a steady voltage of around $200 \mathrm{mV}$. This steady voltage would not normally have triggered off the fetal monitor, but we found that any movement of the electrode caused a fluctuation in voltage which the monitor could interpret as a "fetal heart rate." This case illustrates a potential problem when monitoring the fetal heart rate with the type of scalp electrode described.

We thank Mr A Iles of the department of medical physics at Southmead Hospital for the electronic testing of the scalp electrode.

'Brandt H, Fischer WM. Kardiotokographic. Stuttgart: Georg Thieme Verlag, 1976.

2 Paul RH, Petri EH. Fetal intensive care: current concepts. University of Southern California School of Medicine, 1973.

${ }^{3}$ Perkins RP, Soules MR. Misdiagnosis of fetal heart rate: an unusual case of mistaken identity. Rocky Mountain Medical fournal 1977;22: 207-9.

- Fehrmann H. Misdiagnosis of fetal heart rate during a twin labour. $B r f$ Obstet Gynaecol 1980;87:1174-7.

(Accepted 7 March 1984)

Department of Obstetrics and Gynaecology, Southmead Hospital, Bristol BS10 5NB

FRASER N MCLEOD, MRCOG, senior registrar

DAVID MCCOY, FRCS, FRCOG, consultant obstetrician and gynaecologist

\section{Artefactual fetal heart trace in an undiagnosed dead fetus}

Electronic monitoring of the fetal heart rate during labour is an established practice in most obstetric units. We describe an unusual case in which a high quality fetal heart trace was obtained from a scalp electrode attached to a macerated dead fetus, probably as a result of electrolytic voltage production in the scalp electrode.

\section{Case report}

The patient, a 35 year old primigravida, was admitted at term with a history of absent fetal movements for two days, during which she had experienced intermittent uterine contractions. No fetal heart was heard on auscultation with a Pinnard stethoscope or obtained using an external ultrasound transducer. On vaginal examination old, thick meconium was draining and the cervix was dilated $4 \mathrm{~cm}$. A disposable Copeland fetal scalp electrode (A W Showell Ltd) was applied and connected to a Sonicaid FM 3 fetal monitor. Surprisingly a very clear fetal heart recording was obtained (see figure). A maternal tachycardia of 90 beats/min was present, reaching a maximum of 110 beats/min on occasions. In view of the irregularity of the fetal heart trace we tried to obtain a sample of fetal blood. On direct vision through an amnioscope maceration of the fetal head was apparent, and intrauterine death was diagnosed. Labour proceeded and a macerated stillborn girl was delivered, weighing $3620 \mathrm{~g}$.

\section{Comment}

Electronic monitoring of the fetal heart by a scalp electrode is usually a reliable guide to the condition of the fetus during labour, but one must be aware of the possibility of recording the maternal heart rate through a dead fetus. ${ }^{12}$ Conversely, fetal death has been diagnosed because of suspected transfetal recording of the maternal pulse when the fetus was in fact alive ${ }^{3}$ - the "Lazarus syndrome." The death of a first twin has been missed because the second twin's heart rate was recorded by a scalp electrode attached to the first. ${ }^{4}$ skeletal disorders are being treated by the intralesional instillation of corticosteroids (often mixed with local anaesthetic). These conditions include humeral epicondylitis, tenosynovitis, and bursitis as well as cystic acne vulgaris and hypertrophic keloid. This form of treatment is remarkably free of local and systemic complications but I report here local skin depigmentation that occurred at the site of injectionan unusual side effect that is particularly disconcerting to patients with deeply coloured skin.

\section{Case 1}

A 22 year old African woman complained of locally painful swellings related to both tibial tuberosities. Radiographs indicated the cause to be small, ununited ossicles in the ligamentum patellae, and courses of short wave diathermy and ultrasound were prescribed without effect. The more painful lesion on the right was therefore injected with $40 \mathrm{mg}$ methylprednisolone (Depomedrone). This relieved her pain and the procedure was repeated two months later on the left side with the same degree of success. Eight weeks after the second injection discrete areas of almost complete depigmentation, each measuring about $15 \times 10 \mathrm{~mm}$, appeared at both injection sites (see figure). There was no associated atrophy of the subcutaneous tissues. Normal pigmentation of the skin gradually returned, but it took two months on the right side and 11 months on the left.
An increasingly large number of localised cutaneous and musculo- 


\section{Case 2}

A 43 year old negress complained of discomfort around the lateral aspect of her left wrist. There was no clinical evidence of tenosynovitis, and radiographs showed degenerative changes around the scaphoid articulations. The area was infiltrated with $25 \mathrm{mg}$ hydrocortisone (Hydrocortistab), which completely relieved her symptoms. Within 48 hours, however, an area of almost complete depigmentation measuring about $20 \times 15 \mathrm{~mm}$ appeared over the anatomical snuff box. There was no subcutaneous atrophy and the degree of depigmentation remained unchanged over the following six months.

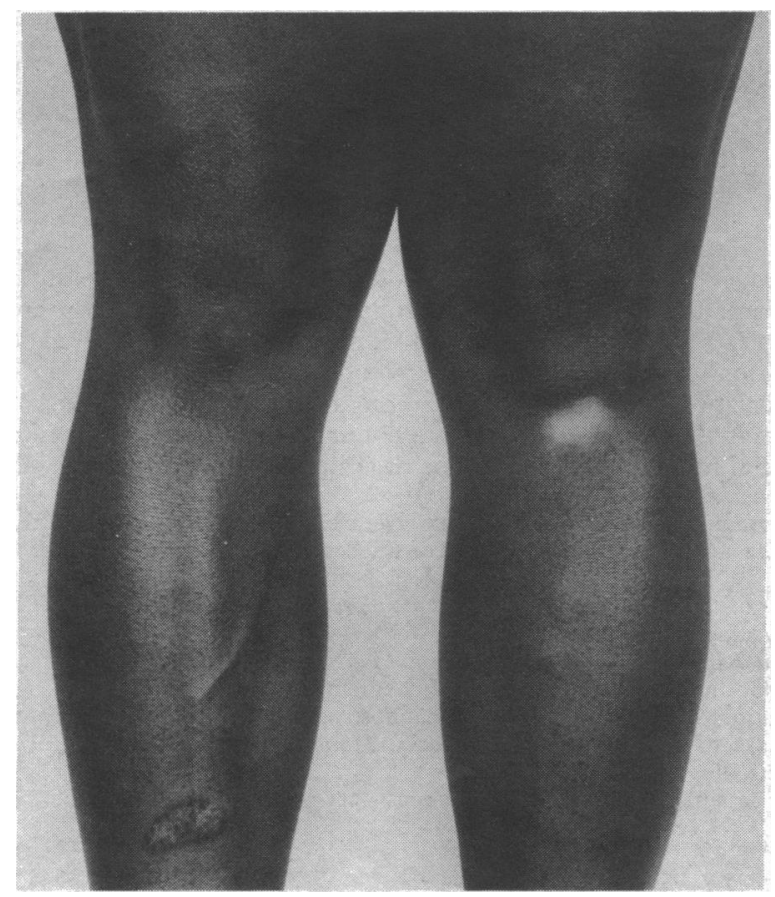

Area of almost complete skin depigmentation six months after the injection.

\section{Comment}

The side effects associated with the long term administration of corticosteroids are well known but relatively few complications have been reported after a single injection. Infection is probably the most important, but subcutaneous atrophy may occur, resulting in localised skin depression. ${ }^{1-3}$ It has therefore been suggested that intralesional doses are not placed too superficially. ${ }^{12}$

Depigmentation is an unusual and distressing side effect of this form of treatment, and the Committee on Safety of Medicines is aware of only one further case. This occurred in an African woman who received one injection of methylprednisolone for tennis elbow. At the time of the report (three months after the onset of the depigmentation) there were no signs of recovery.

The cause of the depigmentation is not clear, but it may be related to either the steroid or to one of the supposedly biologically inactive constituents of the vehicle. Review of published reports has shown no reports of depigmentation due to any of these compounds, so the depigmentation was probably caused by the steroids themselves. Several hypotheses have been advanced to explain the dermatological side effects of steroid therapy, including the mechanical effects of oedema, ${ }^{2}$ a direct cytotoxic effect, ${ }^{4}$ changes in ground substance, ${ }^{2}$ and vasoconstriction. ${ }^{5}$
Alternative methods of treatment should therefore be considered before potent corticosteroids are injected directly into superficial musculoskeletal or cutaneous lesions. This is especially important when these are situated in easily visible sites in patients with deeply pigmented skin.

I thank Professor R B Duthie for allowing me to report patients under his care and Mrs Sandra Newman for secretarial help.

${ }^{1}$ Shetman D, Hamorick GW Jr, Wilson CE. Cutaneous changes following local injection of triamcinolone. Arch Dermatol 1963;88:820-8.

2 DiStefano V, Nixon JE. Steroid-induced skin changes following local injection. Clin Orthop $1972 ; 87: 254-6$.

${ }^{3}$ Lund IM, Donde R, Knudsen EA. Persistent local cutaneous atrophy following corticosteroid injection for tendinitis. Rheumatol Rehab 1979;18:91-3.

4 Feldman JD. The in-vitro reaction of cells to adrenal cortical steroids with special reference to lymphocytes. Endocrinol 1950;46:552.

${ }^{5}$ McKenzie AW, Stoughton RB. Method for comparing percutaneous absorption of steroids. Arch Dermatol 1962;86:608.

(Accepted 15 March 1984)

Nuffield Department of Orthopaedic Surgery, Nuffield Orthopaedic Centre, Oxford OX3 7LD

RAYMOND J NEWMAN, DPHIL, FRCs, MRC training fellow (current Hunterian Professor, Royal College of Surgeons of England

Correspondence to: University Department of Orthopaedic Surgery, Western Infirmary, Glasgow G11 6NT.

\section{Value of routine chest radiography in an acute geriatric unit}

Chest radiography is a recognised screening procedure for newly admitted patients aged over 60 . We decided to assess how widespread and useful is this policy.

\section{Methods and results}

A questionnaire was sent to 97 departments of geriatric medicine to determine prevailing policy. Also 200 consecutive admissions to Northwick Park Hospital were assessed prospectively during a three month winter period. The diagnoses and proposed treatments were determined from history and clinical examination. A single frontal chest $x$ ray film was then obtained and its effect on the clinical diagnosis and treatment documented.

The mean ages of the 131 female and 69 male patients were 82 and 80 years respectively. In 140 instances this was their first admission to the unit. Questionnaires were returned by 85 consultants and indicated that two thirds of hospitals obtained a routine film for all patients on admission. The table shows the results of the clinical survey. Fractionally under half of the chest films were abnormal. The management value of the films was placed into one of two categories: in category 1 (38 patients) the results of radiography affected management in either a positive manner-for example, when a bronchial carcinoma was detected-or negative manner-for example, no evidence of a bronchial carcinoma when this had been a possible diagnosis. Nineteen of the 38 patients had presented with cardiorespiratory symptoms. There were nine patients with toxic confusional states in whom radiography was useful by making it likely or unlikely that the respiratory or cardiovascular system was the underlying cause. In five patients admitted with bone pain the chest films influenced management-for example, by assessing secondary deposits in ribs or by making it likely or unlikely that a rib fracture was present.

In category 2 (162 patients) the chest film was either normal (102) or abnormal $(60)$ but did not affect management. These patients included five with cardiorespiratory symptoms in whom radiography did not confirm

\begin{tabular}{|c|c|c|c|c|c|}
\hline \multirow[b]{2}{*}{ Category of management value of chest film } & \multicolumn{4}{|c|}{ Clinical presentation } & \multirow[b]{2}{*}{$\begin{array}{l}\text { Total } \\
(\%)\end{array}$} \\
\hline & $\begin{array}{l}\text { Cardiorespiratory } \\
\text { symptoms or signs }\end{array}$ & $\begin{array}{l}\text { Toxic confusional } \\
\text { state }\end{array}$ & $\begin{array}{l}\text { Bone (thoracic) } \\
\text { pain }\end{array}$ & Miscellaneous* & \\
\hline $\begin{array}{l}1 \text { (normal or abnormal and influenced diagnosis or treatment) } \\
2 \text { (normal or abnormal and did not influence diagnosis or treatment) }\end{array}$ & $\begin{array}{l}19 \\
62\end{array}$ & $\stackrel{9}{9}$ & $\begin{array}{r}5 \\
12\end{array}$ & $\begin{array}{r}5 \\
88\end{array}$ & $\begin{array}{r}38(19) \\
162(81)\end{array}$ \\
\hline Total & 81 & 9 & 17 & 93 & $200(100)$ \\
\hline
\end{tabular}

-This group was distinct from the others and included patients with parkinsonism, anaemia, depression, dementia, falls, leg ulceration, and cerebrovascular disease. 